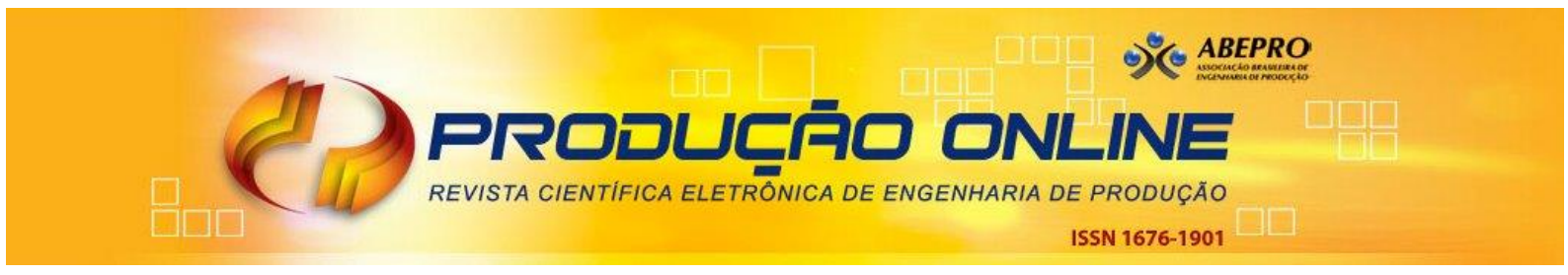

\title{
QUAL O SIGNIFICADO DE VALOR? UMA ABORDAGEM BASEADA EM DIFERENTES PERSPECTIVAS
}

\section{WHAT VALUE MEANS? AN APPROACH BASED ON DIFFERENT PERSPECTIVES}

\author{
Elias Hans Dener Ribeiro da Silva*E-mail: elias.hans@pucpr.br \\ Edson Pinheiro de Lima ${ }^{*, * *}$ E-mail: e.pinheiro@pucpr.br \\ Sérgio Eduardo Gouvêa da Costa*,** E-mail: s.gouvea@pucpr.br \\ *Pontifícia Universidade Católica do Paraná (PUCPR), Curitiba, PR \\ **Universidade Tecnológica Federal do Paraná (UTFPR), Curitiba, PR
}

\begin{abstract}
Resumo: A pesquisa relacionada ao desenvolvimento e conceituação de valor envolve diferentes áreas do conhecimento e é caracterizada por um desenrolar temporal associado à gênese e evolução dos sistemas econômicos. Um número significativo de estudos nessa área ao passar dos anos tem sido direcionado a aspectos puramente econômicos, principalmente no que se refere à análise de criação de valor pelas organizações. O presente artigo tem como objetivo revisitar o conceito de valor por meio do paradigma econômico-social e utiliza de uma revisão de literatura fundamentada em diferentes disciplinas que contribuem para definir conceitualmente os determinantes da criação de valor. Observa-se que a sustentabilidade empresarial e as técnicas relacionadas à gestão de operações vêm sendo muito estudadas nos últimos anos, sendo a sustentabilidade considerada de "valor intangível", porém elevado, tanto quanto valores de credibilidade e reputação organizacional. O trabalho contribui na identificação e conceituação dos determinantes da criação de valor, além de verificar que a sustentabilidade é um dos conceitos fortes na agenda estratégica das organizações e uma importante orientação para criação e manutenção de valor em uma perspectiva de longo prazo.
\end{abstract}

Palavras-chave: Conceito de Valor. Criação de Valor. Pesquisa Bibliográfica. Sustentabilidade.

\begin{abstract}
The research related to the development and value concept involves different areas of knowledge and is characterized by a temporal course associated with the genesis and evolution of economic systems. A significant number of studies in this area over the years has been directed to purely economic aspects, particularly with regards to the analysis of value creation by organizations. This article aims to revisit the concept of value through economic-social paradigm by using a literature review based on different disciplines that contribute to conceptually define the determinants of value creation. It was observed that corporate sustainability and operations engineering techniques have been widely studied in recent years, with sustainability being referenced as "intangible value", as well as credibility and organizational reputation. This research contributed verifying sustainability as one of the key concepts in the strategic agenda of organizations and an important guidance on value creation and maintaining long-term business.
\end{abstract}

Keywords: Concept of Value. Value Creation. Bibliographic Research. Sustainability.

\section{INTRODUÇÃO}

Valor é investigado e conceituado em diferentes áreas do conhecimento, sendo objeto de estudo da filosofia, sociologia, economia, psicologia, antropologia e 
política, possuindo nas ciências econômicas uma interpretação predominantemente material e em contrapartida a sociologia reconhece os valores como fatos sociais. Dentre essas áreas do conhecimento, o valor como conceito teve seu estudo aprofundado em diferentes épocas, sendo nas épocas antigas uma investigação mais voltada à filosofia e em tempo atuais voltadas à economia.

Além disso, dentro de um mesmo campo de estudo, o conceito de valor tem diferentes interpretações, sofrendo também mudanças evolutivas de percepção e/ou recaracterização, influenciadas muitas vezes pelo ambiente externo e cultural, além do aumento da complexidade e instabilidade da sociedade moderna.

O último e mais recente tema para discussão que tem sido abordado, influenciado pelas demandas externas, é a questão da sustentabilidade, na qual já existe uma pressão para que a sociedade contribua para um desenvolvimento sustentável e suas organizações adicionem valor aos seus produtos e serviços de forma sustentável, contribuindo nas perspectivas financeira, ambiental e social.

Porém, como abordado por Freese (1997), manter a sustentabilidade cria um dilema entre os valores coletivos da sociedade e os valores dos indivíduos. Portanto, para resolver este problema, mais atenção deve ser dada para os mecanismos de criação de valor, pois é aparentemente impossível de alcançar uma solução a partir de pontos de vista independentes, como a tecnologia, economia ou psicologia. Em vez disso é importante estudar os problemas por meio da integração de alguns aspectos de valor em relação à criação de valor sustentável na sociedade, sendo necessário repensar o conceito de valor das relações entre os seres humanos, produtos e também da sociedade como problemas de tomada de decisão.

Segundo Dicio (2014), determinante é tudo aquilo que determina, que é causador ou que possa ser considerado motivo ou razão para determinado resultado.

Sendo assim, esse artigo tem como objetivo a caracterização do conceito de valor por meio do paradigma econômico-social e verificar quais são os determinantes que influenciam na criação de valor. Tal conceito será trabalhado sob diferentes perspectivas, desde o conceito filosófico dos sábios da Grécia antiga, até os mais recentes estudos que abordam os conceitos e determinantes de valor sustentável, passando também pela ótica econômica, organizacional e de gestão de operações. 
Este trabalho é caracterizado como teórico e é baseado em revisão bibliográfica, no qual os termos referentes ao conceito de valor foram pesquisados por palavras-chave dentro de bancos de dados acadêmicos e, dentro deste conjunto de artigos selecionados, foi realizada uma análise de conteúdo baseado em colagens de conceito.

\section{A EVOLUÇÃO DO CONCEITO DE VALOR}

Acredita-se que a primeira investigação acadêmica sobre o conceito de valor foi realizada por sábios da Grécia antiga. Axiologia, do grego 'axios' (valor) e 'logia' (estudo) é a disciplina que estuda os valores de uma maneira sistemática. A Figura 1 apresenta um esboço da genealogia da axiologia no ocidente, desde a época do grego antigo até o presente, mostrando pessoas e/ou instituições importantes, juntamente a algumas palavras-chave.

Figura 1 - Genealogia da Axiologia

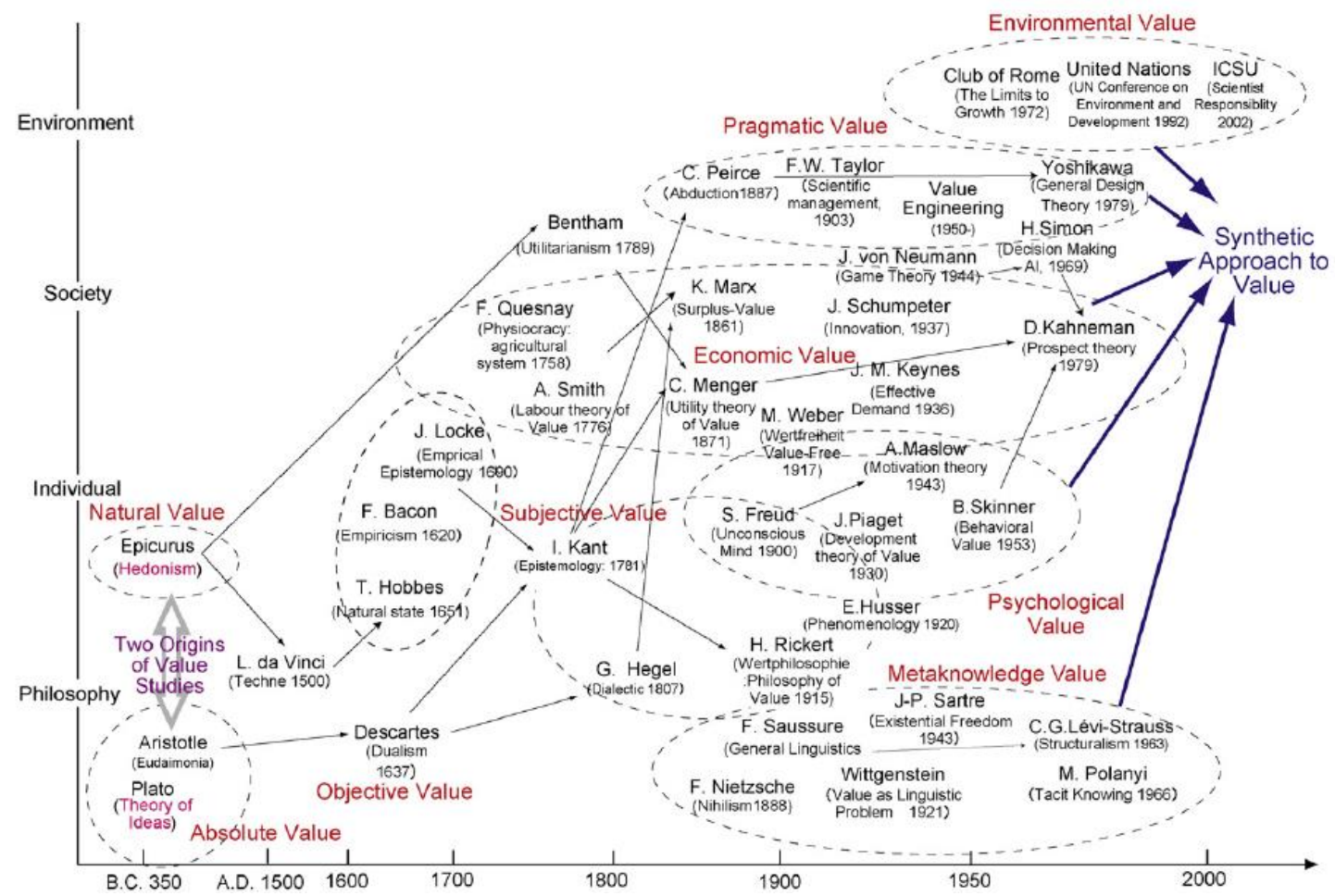

Fonte: Ueda et al. (2009)

Ueda et al. (2009) citam que duas origens importantes da teoria de valores prevaleceram: a "Teoria de formas (ou Teoria das Ideias)", formulada por Platão e o Revista Produção Online, Florianópolis, SC, v.15, n. 4, p. 1326-1350, out./dez. 2015. 
"hedonismo", que teve origem no pensamento de Epicuro. A Teoria das Formas de Platão afirma que os valores existem como realidades absolutas que são independentes do mundo material e das limitações da sensação humana. Em contrapartida, Epicuro enfatizou o prazer como o objetivo mais importante dos seres humanos. As pessoas devem se esforçar para maximizar o prazer e minimizar a dor. Em um sentido limitado, valor reside na natural busca humana de prazer (STAINTON, 2001; SCHMIDT-PETRI, 2005).

Apesar de duas atitudes diferentes relacionados aos valores existentes, a principal questão abordada pelos filósofos da Grécia antiga era como as pessoas poderiam viver bem. Por conta disso, é necessário considerar o que são valores corretos para as pessoas. Por isso, é importante examinar por que as pessoas começaram a estudar os problemas de valor em diferentes períodos da história (UEDA et al., 2009).

No século 17, a retomada da noção de valor começou com o ressurgimento da noção subjetiva de bem, proposto por Hobbes (WATKINS, 1965). O autor explicou cientificamente as conexões lógicas entre os fenômenos da vida social e suas causas. Em uma época de frequentes guerras, o autor descreve a ordem como sendo totalmente útil e valiosa para a vida das pessoas, pois é um instrumento necessário contra as brutalidades da guerra. Segurança, proteção e paz, desejada por todos como valores extremos, são alcançados por meio de um "contrato social" onde todos os homens renunciam seu egoísmo natural, ambição e desejo de poder em favor de uma autoridade política superior (monarquia absoluta) que todos devem obedecer.

No século 18, por outro lado, os filósofos começaram a estudar a subjetividade dos valores. Segundo Hacking (1979), epistemologia, ou Teoria do Conhecimento, é um ramo da filosofia preocupado com a natureza do conhecimento, tais como verdade, crença e justificação.

Lotze (1864), por sua vez, em seu livro Mikrokosmos, defende uma distinção entre "ser" e "valor". O "mundo dos valores" é distinto do "mundo dos entes". Os entes devem ser estudados pelas ciências da natureza, já os valores são assunto das ciências do espírito ou da cultura. Se o "ser" dos entes é algo que se apreende ao intelecto, o "valor" é algo que se aprende pelo "sentimento de estima", uma realidade psicossocial e cultural. O "sentimento espiritual de estima", sugere Lotze, é 
o instrumento da razão para a organização valorativa ou axiológica da realidade (TEIXEIRA, 2008).

Valor subjetivo, por sua vez, ganhou destaque como uma das principais preocupações para a psicologia no final do século 19. Contudo, seria um problema difícil para psicólogos definir valores como faziam os filósofos na mesma época. Freud, que fundou a escola psicanalítica da psicologia, analisou valores humanos naturais do ponto de vista da inconsciência (VALENSTEIN,1989). Piaget estudou problemas de valor do ponto de vista do desenvolvimento cognitivo da criança, particularmente abordando esquema de mudanças em vários estágios de desenvolvimento (FELDMAN, 1997). Em Behaviorismo, do início do século 20, os valores foram estudados do ponto de vista da aprendizagem (ZURIFF, 2002).

Problemas de valor também são descritos na literatura da psicologia humanista de meados do século 20. Maslow (1943) desenvolveu a teoria da motivação humana, baseada em uma hierarquia de necessidades, e vê os valores desde um ponto de vista de necessidades fundamentais. No topo desta hierarquia ele aponta as necessidades de autorrealização, tais como valor, criatividade e moralidade, que são evitados em outras áreas de pesquisa psicológicas.

A partir da década de 1960 até hoje, muitos psicólogos têm sido fortemente afetados pelas ciências cognitivas e atualmente a abordagem cognitiva tornou-se uma das correntes principais em muitas áreas de pesquisas psicológicas (BEST, 1998). Infelizmente, em psicologia cognitiva, os valores não são explorados ativamente porque são difíceis de investigar de um ponto de vista de processamento de informação. Isso pode ser verdade, não só na psicologia, mas também em outras ciências cognitivas. É difícil definir conceitos abstratos como valores mantidos por seres humanos usando manipulação simbólica. Por essa razão, os estudos de valor em muitas áreas acadêmicas apresentam períodos em branco nas últimas décadas (UEDA et al., 2009).

\section{O VALOR NO AMBIENTE ECONÔMICO E ORGANIZACIONAL}

Nos últimos anos, o estudo do valor ganhou grande espaço também na perspectiva econômica. Em fisiocracia, muitas vezes designado como a origem de teorias da economia, o valor é definido como o volume de produtos líquidos de suas indústrias, e não os estoques de ouro e prata. Especialmente, é considerada a Revista Produção Online, Florianópolis, SC, v.15, n. 4, p. 1326-1350, out./dez. 2015. 
agricultura como a única atividade que gerou um produto líquido. Esta fisiocracia posteriormente também afetou as ideias de Adam Smith (SPIEGEL, 1983).

Smith reforçou a economia clássica com seu conceito de" Riqueza das Nações" (SMITH, 1776). Neste tratado, o valor foi classificado em dois tipos: valor de uso e valor de troca. O valor de uso é a utilidade de um produto, enquanto que o valor de troca é igual à proporção relativa com que um determinado produto pode ser trocado por um outro produto. Smith considerou que o trabalho é a medida real do valor de troca. Por isso, ele desenvolveu a teoria do valor-trabalho.

Marx também elaborou sua teoria do valor-trabalho e seu conceito de maisvalia (MARX, 1867). Ele argumentou que a exploração acabaria por gerar uma queda da taxa de lucro e um colapso do capitalismo industrial. Baseado em sua ideia, a economia marxista moderna foi construída.

No campo da engenharia o principal desafio é como produzir bens ou serviços com maior função a um custo menor. Mesmo que a definição de custos mais baixos possa ser facilmente perceptível a partir de um ponto de vista econômico, a maior função não é facilmente definida.

Neste sentido, Walters e Lancanster (2000) definem "valor" como o conjunto de benefícios e utilidades proporcionados por um produto ou serviço, menos o seu custo de aquisição. Desta forma, a percepção de valor pelo consumidor final é a diferença entre os benefícios recebidos e o montante financeiro pago.

Porter (1998) observa que uma empresa não agrega valor somente pelo processamento de recursos, mas também por meio da rede de relações e interações que cria, envolvendo agentes internos e externos, viabilizando o suprimento de insumos e a transformação e a distribuição de produtos. Esse conjunto de atividades, segundo o autor, pode ser também chamado de cadeia de valor. Assim, entende-se que a cadeia de valor de uma empresa estende-se para além das fronteiras da organização, inserindo-a em um sistema maior, por meio de um processo de inter-relações e interdependência.

A habilidade de compartilhar atividades na cadeia de valor é a base para a competitividade empresarial, pois partilha e realça a vantagem competitiva por aumentar a diferenciação (PORTER, 1987). Desta forma, a produtividade, a qualidade e a redução de custos, embora não devam ser ignorados pelos gestores, não são mais geradores de vantagens competitivas sustentáveis, pois se tornaram o mínimo requerido para a sobrevivência da empresa.

Revista Produção Online, Florianópolis, SC, v.15, n. 4, p. 1326-1350, out./dez. 2015. 
A gestão da cadeia de valor envolve a identificação do critério de valor para o consumidor final, entendendo os fatores críticos de sucesso para o atendimento de suas prioridades, visando a criação de vantagem competitiva em toda a cadeia de valor (WALTERS e LANCASTER, 2000). Portanto, o compartilhamento de informações sobre o consumidor final por meio dos elos da cadeia de valor passa ser crucial.

Dentro de uma organização as diferenças entre as cadeias de valores concorrentes são determinantes para criação de uma vantagem competitiva. Desta forma o valor é definido por Porter (1998) como o montante que os compradores estão dispostos a pagar por aquilo que uma empresa lhes oferece. Medida pela receita total, uma empresa é considerada rentável se o valor que ela impõe ultrapassa os custos envolvidos na criação do produto. Assim, o valor e não os custos devem ser utilizados para análise da posição competitiva.

Inevitavelmente, a percepção do significado de valor deve passar pelo cliente, o qual extrapola a percepção de custos. Csillag (1995) apresenta quatro tipos de valor econômico:

- Valor de custo: caracterizado como o total de recursos medido em dinheiro necessário para produzir ou obter um item;

- Valor de uso: medida monetária das propriedades ou qualidades de desempenho de uso, trabalho ou serviço;

- Valor de estima: medida monetária relacionada das propriedades ou características de um item que tornam desejável sua posse;

- Valor de troca: relacionado à medida monetária das propriedades ou qualidades de um item que tornam viável sua troca por outro item.

A cadeia de valores exibe o valor total, consistindo de margem e atividades de valor. A margem é a diferença entre o valor total e o custo coletivo da execução das atividades de valor. Estas não se caracterizam por atividades independentes dentro da empresa, mas sim interdependentes, que estão relacionadas por meio de "elos" dentro da cadeia de valores. Desta forma, tais elos são relações entre o modo como uma atividade de valor é executada e o custo ou desempenho de outra (PORTER, 1998).

Relvas (1996) mostra que o estudo da cadeia de valores contribui de diversas maneiras para a identificação, construção e manutenção de vantagens competitivas. 
Isso é viabilizado pela exploração das inter-relações e interações, pela análise do modo como cada atividade de valor é executada para determinar sua contribuição na formação do valor para o consumidor e pela comparação com cadeias de valores de seus concorrentes.

\section{O VALOR NA GESTÃO DE OPERAÇÕES}

As organizações além de buscarem constantemente a manutenção de suas vantagens competitivas levando o maior valor percebido ao cliente, dispendem consideráveis esforços e recursos para promover a melhoria contínua do processo de manufatura.

Segundo Corrêa e Gianesi (1996), há um movimento de reconhecimento do papel estratégico da manufatura na otimização do processo produtivo e redução de seus custos. Assim, grande parte das empresas tem se empenhado na implementação de processos de transformação de acordo com técnicas da filosofia de produção enxuta (Lean Production).

O termo lean production (produção enxuta) foi proposto por pesquisadores americanos traduzindo ao mundo ocidental as técnicas utilizadas pela Toyota, introduzidas por Womack, Jones e Roos (1990). Posteriormente, Womack e Jones (1996) ampliaram o termo para "Pensamento Enxuto" (Lean Thinking), enfatizando que o mesmo se aplica a toda a empresa.

De acordo com Womack e Jones (1996), o pensamento enxuto é uma forma de especificar valor, alinhar na melhor sequência as ações que criam valor, realizar essas atividades sem interrupção toda vez que alguém as solicita e realizá-las de forma cada vez mais eficaz. Assim o pensamento enxuto se torna uma forma de fazer mais com cada vez menos, ou seja, menos esforço humano, equipamento, tempo e espaço e, ao mesmo tempo, aproximar-se cada vez mais de oferecer aos clientes exatamente o que eles desejam. Desta forma, o fundamento deste pensamento é localizar e eliminar os desperdícios, sendo eles tudo o que não agrega valor ao cliente.

É válido apresentar que houve significativas melhorias em empresas que adotaram a produção enxuta em termos de redução do tempo de produção, além da melhoria na qualidade (WOMACK et al., 1990). 
Nesse sentido, vale ressaltar que a maioria dos benefícios aos consumidores, na medida em que não implicavam em elevação significativa dos preços, se constituíam em um processo que agregava cada vez mais valor aos produtos fabricados. Como resultado, o nível de satisfação dos consumidores elevou-se (BRITO, 2003).

Em manufatura existem dois tipos de operações: as que agregam valor, ou seja, as que realmente transformam a matéria prima, modificando sua forma; e as que não agregam valor, como transporte de peças, movimentação, retrabalho, etc. e que podem ser consideradas como perdas.

$\mathrm{Na}$ visão de Ford, o desperdício dos materiais é uma consequência cuja causa encontra-se em uma perda muito mais relevante, associada à incorreta utilização das pessoas nos processos de produção, em virtude da deficiente análise dos processos de fabricação que geram estas perdas (ANTUNES, 2008).

As atividades que transformam a matéria prima constituem o processamento e aumentam o seu valor agregado, e quanto maior o valor agregado maior será a eficiência da operação (OHNO, 1997).

Segundo Elias (2001), pode-se representar valor como função/custo. O cliente está interessado nas funções dos recursos (produto, serviço, processo, atividade etc.) e quanto melhor as funções forem desempenhadas ao menor custo, maior será o valor.

Neste sentido, as ferramentas associadas à produção enxuta facilitam a busca pelo que agrega valor ao consumidor, consistindo, basicamente, na melhor alocação dos recursos de produção disponíveis, qualificação da mão-de-obra, redução de estoques e racionalização do tempo, que contribuíram para a redução de custos. (ZAWISLAK et al. 2000).

Desta forma, todas as funções que o produto/serviço apresentar que não atendam às necessidades do usuário devem ser eliminadas, uma vez que não the dão maior valor, apenas agregam custo.

Entre os princípios relacionados ao pensamento enxuto, Womack e Jones (1996) destacam dois:

- Valor: sendo a capacidade oferecida a um cliente no momento certo a um preço adequado, conforme definido pelo cliente; 
- Fluxo de valor: sendo as atividades específicas necessárias para projetar, produzir e oferecer um produto específico, da concepção ao lançamento, do pedido à entrega, e da matéria-prima às mãos dos clientes.

Womack (2006) explica que todo o valor produzido por uma organização é o resultado final de um complexo processo e uma série de ações, que os adeptos lean também chamam de fluxo de valor. $O$ autor explica que o que mais interessa ao cliente, seja ele interno ou externo, é que o valor flua para ele, não estando interessado nos esforços de melhoria de cada produto para a organização e nem no valor fluindo para outros clientes.

Womack e Jones (1996) ainda destacam que o valor deve ser sempre especificado pelo cliente final, sendo o ponto inicial de qualquer processo. A cadeia de valor são todas as etapas ligadas às tarefas de concepção e lançamento de um novo produto, gerenciamento da informação e transformação física. O objetivo do pensamento de fluxo é a eliminação total das paralisações em todos os processos de produção.

Para minimizar os desperdícios de produção e seus efeitos, prosseguindo com a busca contínua de "zero defeitos, tempo de preparação zero, estoque zero, movimentação zero, quebra zero, lead time zero e lote unitário", a Produção Enxuta utiliza de algumas técnicas e ferramentas.

Dentre essas técnicas encontra-se o Mapeamento do Fluxo de Valor (VSM Value Stream Mapping). O VSM é uma técnica utilizada para entender a forma atual do funcionamento da empresa, seus desperdícios de recursos e ajudar no desenvolvimento de um fluxo de valor futuro com menos desperdícios (TURKYILMAZ et al., 2013). VSM é uma das técnicas chaves de produção enxuta para identificar oportunidades para outras diversas técnicas de produção enxuta (AR; ASHRAF, 2012).

Essa ferramenta introduzida por Rother e Shook (2003), é um método de modelagem relativamente simples e de baixa tecnologia com um procedimento para construção de cenários de manufatura. Essa modelagem leva em consideração tanto o fluxo de materiais como o fluxo de informações e ajuda significantemente na visualização da situação atual e na construção da situação futura (VIEIRA, 2006).

A ferramenta foi construída com a intenção de redução de lead time, ocasionando, por conseguinte a redução de desperdícios. Para Ohno (1997) invariavelmente essa redução ocasiona um impacto positivo sobre todos os objetivos Revista Produção Online, Florianópolis, SC, v.15, n. 4, p. 1326-1350, out./dez. 2015. 
de desempenho descritos por Slack (1996) - custo, qualidade, flexibilidade, velocidade de entrega e confiabilidade.

Outra técnica importante utilizada dentro da gestão de operações é a Análise de Valor e Engenharia de Valor (AV/EV), por analisar por que se faz determinado produto e por que são usados determinados métodos de processamento.

As técnicas da Análise do Valor foram criadas durante a Segunda Guerra Mundial, vista a necessidade de se pesquisar materiais com menor custo e grande disponibilidade, para substituir produtos mais raros e de elevado custo.

Lawrence Miles, criador da AV/EV define valor como uma combinação de desempenho e custo. $O$ valor é aumentado pela redução de custos mantendo-se o desempenho, ou aumentando o desempenho e mantendo-se o custo, desde que as necessidades dos clientes sejam satisfeitas e ele esteja disposto a pagar por mais desempenho (MILES, 1989).

SAVE International (2013) por sua vez define valor como funções divididas por custos ou o desempenho confiável das funções que possam atender as necessidades dos clientes com o menor preço global. Nessa equação, o custo é tangível e facilmente determinado, já o desempenho muitas vezes é mais difícil de ser quantificado. Consequentemente, há uma tendência em sublinhar o aspecto de redução de custos da equação de valor.

A Análise do Valor é um conjunto sistematizado de esforços e métodos destinados a aumentar o valor econômico total de um produto, processo ou serviço, enquanto que a Engenharia do Valor refere-se a produtos, processos ou serviços novos ainda na fase de concepção. Apesar das diferentes utilizações, os termos Análise do Valor (AV) e Engenharia do Valor (EV) passaram a ser usados indistintamente (POSSAMAI, 1997; ABREU, 1996). Os autores explicam que a metodologia da AV/EV identifica a função de um produto/serviço e estabelece um valor para aquela função, visando alcançar tal função com o menor custo possível.

A SAVE International (2013) recomenda uma abordagem sistemática e estruturada de aplicação da metodologia que consiste em 6 fases:

- Informações: Reunir informações para entender melhor o projeto.

- Análise de Funções: Analisar o projeto para entender e esclarecer as funções necessárias. 
- Criativo: Gerar ideias sobre todas as formas possíveis para realizar as funções necessárias.

- Avaliação: sintetizar ideias e conceitos para selecionar planos viáveis de desenvolvimento para melhoria de valor específico.

- Desenvolvimento: Selecionar e preparar as melhores alternativas para aumentar o valor.

- Apresentação: Apresentar a recomendação de aumento de valor para os stakeholders.

O principal benefício da análise de valor e engenharia de valor é a redução de desperdícios. Isso muitas vezes é visto como uma redução de custos, porém, outra perspectiva é que os produtos e processos estão sendo redesenhados para aumentar o valor para o cliente, melhorando a qualidade, confiabilidade e a capacidade de resposta. Além disso, a engenharia de valor pode promover a criatividade, a inovação e a sustentabilidade (ALWERFALLI e CZARNIK, 2010).

Outra ferramenta dentro da gestão de operações que auxilia na gestão de valor é o método de custeio $A B C$, por permitir a análise do valor adicionado das atividades, garantindo competitividade associada à análise estratégica das atividades que não agregam valor (HANSEN; MOWEN, 2011);

O método de custeio Activity Based Costing ( $A B C)$ foi desenvolvido por Cooper e Kaplan (1987) com a finalidade de reduzir as distorções provocadas pelo rateio arbitrário dos custos indiretos, provocado pelos métodos de custeio conhecidos como tradicionais.

Para tanto, ele busca alocar os custos indiretos de maneira menos arbitrária, bem como para subsidiar decisões estratégicas dos gestores e outras decisões que possam afetar a capacidade da empresa e, consequentemente, seus custos fixos e variáveis. A metodologia proposta pelo método tenta associar os custos às atividades desempenhadas pela empresa, considerando a premissa de que os produtos e outros objetos de custeio consomem atividades e estas, por sua vez, consomem os recursos (GARRISON; NOREEN; BREWER, 2007).

Bornia (2009) destaca ainda que o $A B C$ determina quais atividades consomem os recursos da empresa, agregando-as em centros de custos por atividades. Para cada um desses centros atribui-se custos aos produtos, conforme seu consumo de recursos. Desta forma podem-se determinar quais são os produtos 
subcusteados e quais são os supercusteados, auxiliando no melhoramento contínuo das tarefas.

Segundo Garrison, Noreen e Brewer (2007), o método de custeio ABC deve ser implantado em seis etapas, sendo estas: identificar e definir as atividades acumuladoras de custos; vincular os custos gerais diretamente às atividades e objetos de custos; atribuir custos a acumuladores de custos de atividades; calcular taxas de atividades; atribuir custos a objetos de custos por meio do uso de taxas e das medidas de atividades; e, preparar relatórios gerenciais.

Optar pelo método de custeio ABC representa a decisão da organização em estabelecer uma gestão estratégica de custos buscando rastrear as atividades relevantes, ou seja, as atividades que agregam valor, identificando os fatores que conduzem ao consumo de recursos nas operações (HANSEN; MOWEN, 2011). Apesar de mais complexo, este método traz à tona atributos que contribuem na obtenção de vantagens competitivas, como: conhecimento de custos relevantes; capacidade ociosa existente no processo produtivo; rastreamento das atividades que consomem mais recursos, melhoria nos custos que podem ser otimizados; conhecimento mais exato dos custos de cada produto para auxiliar decisões de preço; suporte às decisões entre alternativas do que produzir; eliminar uma linha de produção ou mesmo auxiliar no lançamento de um novo produto (SHANK, 2000; YOUNG; O'BYRNE, 2003; GARRISON; NOREEN; BREWER, 2007; HANSEN; MOWEN, 2011; HORNGREN; DATAR; RAJAN, 2011).

\section{O VALOR NAS OPERAÇÕES SUSTENTÁVEIS}

Em busca de uma nova ordem econômica mundial, onde houvesse um maior equilíbrio entre as dimensões econômica, social e ambiental, em 1987 o documento Nosso Futuro Comum (Relatório da Comissão Brundtland) trouxe o conceito de Desenvolvimento Sustentável, um novo paradigma de desenvolvimento no qual as necessidades do presente são atendidas, sem comprometer a capacidade das futuras gerações de atenderem às suas próprias necessidades (WCED, 1987).

Muitos conceitos sobre o que é uma organização sustentável são propostos por vários autores. O mais difundido no meio empresarial baseia-se na ideia de que as empresas devem se fundamentar no triple bottom-line (TBL). Em suma, o conceito diz que além de gerar resultados econômico-financeiros, as empresas Revista Produção Online, Florianópolis, SC, v.15, n. 4, p. 1326-1350, out./dez. 2015. 
também devem se engajar em ações sociais e zelar pelo meio ambiente (HART; MILSTEIN, 2003).

As organizações começaram a perceber que elas fazem parte de um todo e que para poder evoluir ela deve ser sustentável. Por sua vez, os consumidores estão cada vez mais conscientes do seu poder de transformação social e começam a demandar das organizações maior responsabilidade empresarial no que se refere às questões sociais e ambientais. Desta forma, surge a sustentabilidade corporativa que trata do compromisso organizacional com o desenvolvimento sustentável, ou seja, uma forma de conduzir as atividades empresariais pensando nas pessoas, nos lucros e no meio ambiente (INSTITUTO ETHOS, 2003).

ASSAF NETO (2003) considera que uma empresa somente pode agregar valor quando pode oferecer expectativa de retorno superior a seu custo de capital. Para que a criação de valor tenha uma vertente sustentável é necessário que em todo seu processo de criação e produção contemple todos os critérios necessários a agregação de valor e, para tanto, deve considerar uma estratégia bem definida, garantindo diferencial competitivo.

Para Montgomery e Porter (1998), estratégia é a busca deliberada de um plano de ação para desenvolver e ajustar a vantagem competitiva de uma empresa. Porter \& Kramer (2011) por sua vez consideram que uma empresa obtém vantagem competitiva pela forma como configura sua cadeia de valor, assim como as atividades quanto à criação, produção, venda, entrega e suporte de seus produtos ou serviços.

Para a obtenção de vantagem competitiva, as organizações devem estar atentas, às tendências de mercado, tecnologia disponível, novos materiais e as necessidades dos clientes, buscando constantemente ações que as diferenciem.

Ghemawat (2007) considera que a vantagem competitiva é derivada das diversas atividades que uma empresa realiza ao projetar, fabricar, comercializar, entregar e prestar assistência a seu produto. Cada uma das atividades deve contribuir para a posição relativa de custo da organização e criar uma base para a diferenciação. A cadeia de valor considera de forma particular as atividades estrategicamente relevantes, para definir o comportamento dos custos e as fontes de diferenciação potenciais.

Para Lins et al. (2010), a adoção de métodos operacionais e de produção deve receber investimentos de forma consciente pelas empresas, de forma a Revista Produção Online, Florianópolis, SC, v.15, n. 4, p. 1326-1350, out./dez. 2015. 
assegurar a geração de valor, não apenas para a organização, mas também para as comunidades das regiões que atuam.

Para Hart \& Milstein (2003), a criação de valor sustentável aborda quatro perspectivas das quais as empresas devem atender: (i) A primeira delas é a redução do nível de consumo de matéria-prima e descarte de poluentes, que estão associados à rápida industrialização; (ii) a segunda aborda operações com níveis mais amplos de transparência e responsabilidade; (iii) a terceira busca o desenvolvimento de novas tecnologias com potencial para reduzir os danos sobre o planeta; (iv) e a quarta, trata do atendimento às necessidades da comunidade que está localizada na base da pirâmide de renda do mundo, como forma de determinar a criação e distribuição de renda inclusiva. A Figura 2 apresenta esta configuração.

Figura 2 - Criação de Valor Sustentável

Construindo a oportunidade de amanhã
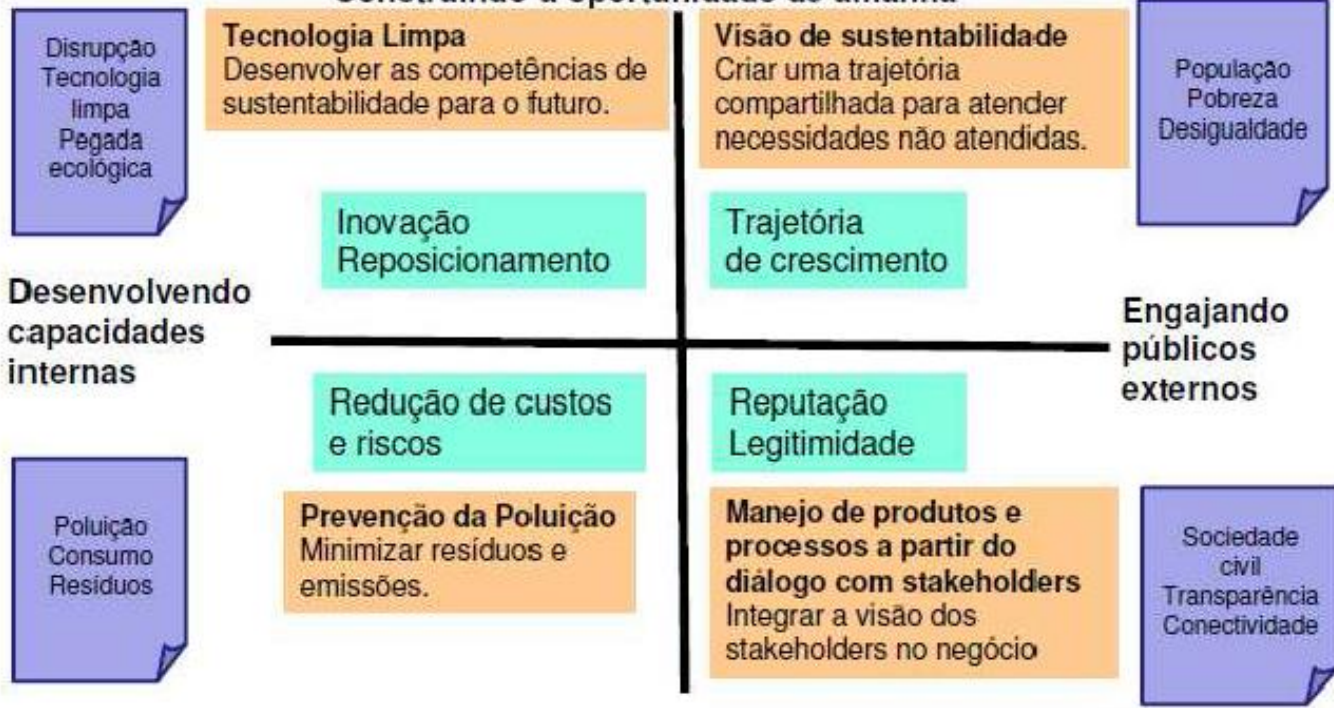

Administrando a empresa de hoje

Dimensōes do Valor para o Acionista

Fonte: Hart e Milstein (2003)

Estratégias

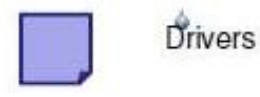

Hart e Milstein (2003) também comentam que uma das grandes dificuldades das empresas ainda é relacionar a sustentabilidade ao objetivo de aumentar o valor para o acionista, sendo que algumas delas utilizam do pressuposto que a criação de um mundo mais sustentável irá exigir que as empresas sacrifiquem os lucros e o valor ao acionista em nome do bem público. Ao partirem de argumentos legais ou morais para a ação das empresas, os executivos inevitavelmente subestimam as oportunidades estratégicas de negócios associadas a esse importante tema. 
Visando evitar esse problema, os executivos necessitam relacionar diretamente a sustentabilidade da empresa e a criação de valor para o acionista. Os desafios globais associados à sustentabilidade, vistos de um ponto de vista de negócios podem ajudar a identificar estratégias e práticas que contribuam para um mundo mais sustentável e, simultaneamente, gerem valor ao acionista. Esta abordagem é definida como a criação de valor sustentável para a empresa.

A criação de valor compartilhado pode ser uma resposta para estas questões também. Porter e Kramer (2011) discutem algumas alternativas de como transformar o modelo capitalista, desencadeando um processo de inovação e crescimento. Eles defendem que o meio empresarial entrou num círculo vicioso, onde a competitividade e o crescimento econômico estão comprometidos. A solução apontada é o alinhamento e união da atividade empresarial com a sociedade, ou seja, a geração de valor econômico de forma a criar também valor para a sociedade.

Porter e Kramer (2011) definem valor compartilhado como as políticas e práticas operacionais que, ao mesmo tempo que aumentam a competitividade de uma organização, também melhoram as condições socioeconômicas nas comunidades em que atua. $O$ foco da geração de valor compartilhado é identificar e ampliar o elo entre o progresso social e o econômico, não consistindo em uma redistribuição, mas sim em um aumento nos ganhos de todos os stakeholders.

Grande parte dos executivos ainda apontam o lucro para o acionista como o objetivo maior das organizações. Porém, atualmente, o lucro é mais um meio do que um objetivo principal. Diversos modelos de negócios inclusivos são projetados voltados ao debate e solução de problemas da sociedade e a estabilidade financeira, obtida por meio de estratégias empreendedoras e de geração de renda, permite o aumento do alcance e impacto das ações. Além disso, Porter e Kramer (2011) defendem três maneiras de uma empresa criar valor compartilhado, sendo elas a reformulação de produtos e mercados, a redefinição da produtividade na cadeia de valor e, por fim, a criação de clusters setoriais de apoio nas localidades da empresa.

Porter e Kramer (2011) definem que a criação de valor econômico compartilhado pressupõe a conformidade com a legislação (compliance) e com normas éticas, bem como a mitigação de qualquer dano causado pela empresa. $A$ oportunidade de gerar valor econômico por meio da criação de valor social será uma das mais poderosas armas para o crescimento econômico mundial. Essa ideia representa uma nova maneira de compreender as necessidades dos clientes, a Revista Produção Online, Florianópolis, SC, v.15, n. 4, p. 1326-1350, out./dez. 2015. 
produtividade e as influências externas sobre o sucesso da empresa. Além disso, essa nova concepção pode ser uma forma de criar valores intangíveis ou de longo prazo, como imagem de marca, moral dos colaboradores, reputação organizacional e potencial para desenvolver novas capacitações e fortalecer a competitividade nos negócios.

Toda organização deve analisar suas oportunidades e tomar suas decisões sob a ótica do valor compartilhado, pois isso irá levar a novas abordagens que gerem mais inovação e crescimento para empresas, além de benefícios maiores para a sociedade (PORTER e KRAMER, 2011).

\section{DISCUSSÃO}

Por meio da revisão bibliográfica foi possível observar a existência de alguns determinantes para a criação de valor, discutidas por diversos autores sob diferentes perspectivas. A Figura 3 buscou fazer um quadro síntese desses determinantes apresentando de forma estruturada em 4 perspectivas.

A primeira delas é o paradigma socioeconômico, no qual buscou-se visualizar os determinantes de criação de valor sob o aspecto humanístico-filosófico, tratando de um contexto macro e inerente à realidade de todas as pessoas e organizações.

A segunda perspectiva é a gestão de operações, em que buscou-se visualizar os determinantes de criação de valor sob um aspecto de processos organizacionais, como meio de gerar valor organizacional.

A terceira perspectiva é a econômica, na qual buscou-se visualizar os determinantes de criação de valor sob um aspecto de resultados, como estágio final (ou finalidade) do processo organizacional.

A quarta e última perspectiva é a do Paradigma de Desenvolvimento Sustentável no qual buscou-se visualizar os determinantes de criação de valor sob um aspecto de contexto micro/operacional. 
Figura 3 - Determinantes para criação de valor
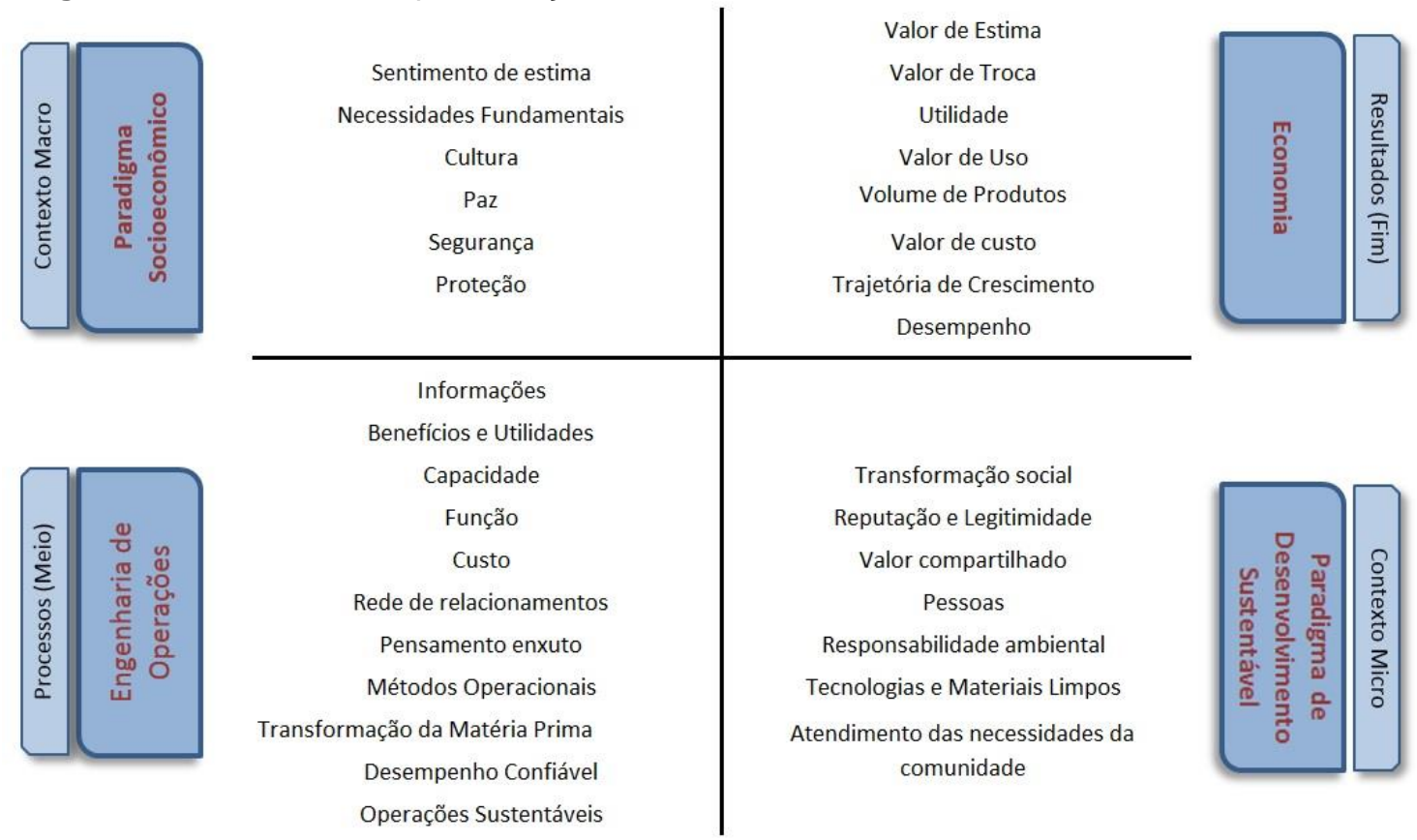

Fonte: os autores (2014)

Repensar o conceito de valor e seus determinantes em um ambiente organizacional é também repensar a estratégia e o como abordar essa mudança estratégica. Esses determinantes classificados sob a ótica dessas 4 perspectivas estão também alinhadas com a proposta de Pettigrew (1987, 1992), que em sua concepção original é um modelo para a análise de todo o conjunto de variáveis e elementos organizacionais (Pereira, 1998). O modelo proposto por Pettigrew permite estruturar o processo de mudança estratégica por meio de três dimensões estratégicas: contexto (Perspectiva 1 e 4), processo (Perspectiva 2) e conteúdo (Perspectiva 3).

Pettigrew (1987, 1992), analisa que a dimensão do "contexto" está relacionada à pergunta "por quê" da mudança e é derivada da análise do ambiente interno e externo da organização. Em suma, o contexto refere-se às forças ambientais e aos aspectos internos que restringem e habilitam as mudanças estratégicas no nível da organização. O conteúdo está relacionado ao "o quê" da mudança e pode estar relacionado ao equilíbrio das ações de exploração. Assim, o conteúdo corresponde às estratégias que realmente são adotadas. O processo, por sua vez, diz respeito ao "como" da mudança, isto é, à maneira em que ela ocorre, e está relacionado ao caráter dinâmico e temporal da mudança estratégica. A visão do processo está alinhada ao conceito de formação da estratégia, levando em 
consideração a trajetória da organização e as diferentes maneiras que conduzem uma empresa para uma estratégia.

A tríade contexto-conteúdo-processo não representa apenas uma forma de explicar o fenômeno da mudança estratégica. A teoria proposta por Pettigrew (1987) fornece uma estrutura metodológica que permite guiar a pesquisa na área e correlacionar diferentes variáveis pertencentes a cada uma das três dimensões. Dessa forma, é possível dispor de uma abordagem integrada de análise, tão valorizada atualmente nos estudos organizacionais (GOHR e SANTOS, 2011).

Essa correlação de variáveis é cada vez mais importante para compreender fenômenos organizacionais e como se cria valor dentro de um ambiente. O que antigamente poderia ser considerado fim, atualmente pode ser considerado apenas um meio, visto à dinâmica das mudanças.

Como exemplo, pode-se citar dentro do ambiente organizacional a evolução do conceito de valor dentro da gestão de operações. Conforme supracitado, Ford associava o baixo custo de produção (e tudo aquilo que impactava nesse baixo custo) como forma de agregar valor, pois o único fim era a rentabilidade financeira.

Quando o paradigma é mudado, os meios devem ser repensados. A qualidade foi somada aos custos para incorporar o conceito de valor, pois permitia um ganho de longo prazo junto aos stakeholders, pois, além de fidelizar o cliente, evitava o desperdício de material e retrabalhos (diminuindo custos).

A ideia de Ford com sua lendária frase "O carro é disponível em qualquer cor, contanto que seja preto", já não cabia mais em um ambiente dinâmico. A incorporação da flexibilidade foi importante na gestão de operações, por criar uma forma de atender a demanda e gerir de forma mais apropriada o negócio. A flexibilidade de produtos/serviços, de compostos, de volume e de entrega foram essenciais para maximizar a agilidade na resposta ao mercado na economia de tempo e na manutenção da confiabilidade. Todos esses fatores, conforme apresentado na Figura 3 são determinantes na criação de valor, através da criação de desempenho confiável, geração de benefícios e utilidades, além da redução de custos.

A evolução desses pensamentos gerou o que é chamado de Produção Enxuta (ou Sistema Toyota de Produção), que nada mais é do que uma filosofia de gestão focada na redução de desperdícios e que inclui diversas ferramentas que buscam aumento da qualidade e redução de tempo e custo.

Revista Produção Online, Florianópolis, SC, v.15, n. 4, p. 1326-1350, out./dez. 2015. 
Percebe-se que a trajetória dos conceitos não foi de mudança, mas sim de desenvolvidos, evolução e aperfeiçoamento. Assim pode ser visto na atual revolução da sustentabilidade, que inclui aspectos humanos ao paradigma econômico-social, onde há estudos que argumentam e defendem que o que já foi desenvolvido até aqui só se manterá para as gerações futuras se houver uma preocupação social e ambiental atrelada.

Assim, a evolução do conceito de valor na gestão de operações, conforme apresentado pela Figura 4 agregou em cada marco da trajetória de evolução novas formas das organizações criarem valor aos stakeholders.

Figura 4 - Evolução do conceito de valor na gestão de operações

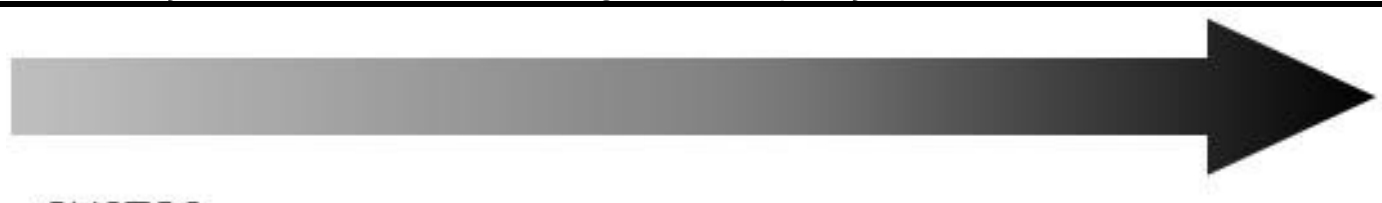

CUSTOS

QUALIDADE

FLEXIBLIDADE

PENSAMENTO ENXUTO

\section{SUSTENTABILIDADE}

Fonte: os autores (2014)

Apesar de esse trabalho abordar de forma mais exaustiva o valor relacionado ao paradigma de gestão de operações dentro do aspecto organizacional, a sumarização da criação e agregação de valor não se resume apenas à isso e aos exemplos supracitados. Diversos outros aspectos se encaixam na evolução da criação de valor organizacional. Como exemplo pode-se citar o determinante "pessoas", que por estar intrinsicamente ligado à ao valor de qualquer organização é um determinante central do paradigma de desenvolvimento sustentável, porém também está ligado ao paradigma socioeconômico (macro), pois determinantes como a cultura, segurança, proteção e paz são fatores necessários para sua evolução. Assim percebe-se que, sob uma visão holística, entregar valor cria valor e isso torna-se um ciclo, que pode-se dizer, virtuoso. 


\section{CONCLUSÃO}

Observa-se que no atual cenário econômico-social o significado de valor vai muito mais além das atividades operacionais, transformação de matéria prima ou volume de produtos. Mesmo pertencente à outra época, Lotze (1894) ainda se mostra coerente quando citou que o valor também está ligado a uma realidade cultural. As novas tendências e a atual complexidade nesse contexto mostram que diversas variáveis devem ser repensadas para potencialização de criação de valor.

Foi possível observar neste artigo que o conceito de valor, quando abordado, não deve abranger apenas uma única faceta, pois seu real propósito é potencializado quando pensado e abordado sob diversas perspectivas, além de construir uma realidade mais coerente e útil do ponto de vista estratégico.

Assim, os determinantes apresentados na Figura 3 podem ser consumidos de forma conjunta e cada organização pode determinar seu conjunto de determinantes de tal forma que melhor represente, crie e entregue valor aos seus stakeholders.

Assim fica claro que empresas com estratégias diferentes oferecem pacotes de valor diferentes, o que também determina uma composição diferente de sua função valor, apesar de todas elas buscarem alcançar como resultado da equação a satisfação dos envolvidos.

Como exemplo de diferentes pacotes de valor a serem entregues, pode-se citar as empresas "comuns" e aquelas que estão migrando seu foco e buscando o desenvolvimento sustentável. Anos atrás o pacote de valor resumido ao desempenho financeiro era suficiente, o que em alguns casos é um fato que não se mostra mais real e a busca por desempenho social e ambiental se torna essencial.

Assim como as técnicas e conceitos de gestão de operações foram fundamentais para as organizações ganharem vantagens competitivas nos últimos anos, o contexto socioeconômico e as pesquisas atuais levam a crer que a criação de valor sob o aspecto de operações sustentáveis beneficiará o crescimento das empresas nos próximos anos, gerando um valor compartilhado, no qual todos os stakeholders são beneficiados.

O presente trabalho rediscutiu o conceito de valor sob diferentes óticas e propôs uma nova análise nesse contexto, mas também apresentou algumas limitações. Apesar de o estudo ter mapeado os determinantes de criação de valor em diversas perspectivas, não criou uma função valor, cujas variáveis são Revista Produção Online, Florianópolis, SC, v.15, n. 4, p. 1326-1350, out./dez. 2015. 
ponderadas quantitativamente. Uma segunda limitação foi não ter testado empiricamente o uso dessas variáveis na criação de valor.

Sendo assim, propõe-se como trabalho futuro o teste empírico do uso de tais determinantes e suas interações para constatação de ganho de valor organizacional. Como segunda sugestão propõe-se verificar estatisticamente se apenas as variáveis quantitativas, ou seja, as relacionadas ao desempenho e ao volume são atualmente utilizadas para caracterizar valor ou variáveis qualitativas, relacionadas à cultura e ao paradigma socioeconômico, também são levadas em consideração.

\section{REFERÊNCIAS}

ABREU, R.C.L. Análise do valor. Rio de Janeiro: Qualitymark, 1996.

ANTUNES, J.; ALVAREZ, R.; BORTOLOTTO, P. KLIPPEL, M. PELLEGRIN, I. Sistemas de Produção: conceitos e práticas para projeto e gestão da produção enxuta. Porto Alegre: Bookman, 2008.

ALWERFALLI, D.; CZARNIK. B. An Overview of Value Engineering in Product Development and Design. In: IIE Annual Conference Proceedings, 2010, Cancún: México. Proceedings... Cancún, 2010. “

AR, R., ASHRAF, M. A. Production flow analysis through Value Stream Mapping: A Lean manufacturing process case study. Procedia Engineering, v.41, p. 1727-1734, 2012. http://dx.doi.org/10.1016/i.proeng.2012.07.375

ASSAF NETO., A . Finanças corporativas e valor. São Paulo: Atlas, 2003.

BEST, J. B. Cognitive psychology. New York: John Wiley \& Sons Inc., 1998.

BORNIA, A. C. Análise gerencial de custos: aplicação em empresas modernas. 2. ed. São Paulo: Atlas, 2009.

BRITO, A. J. A inteligência da produção enxuta. Seminário em Administração FEA-USP, 6 , 2003, São Paulo. Anais... São Paulo, 2003.

COOPER, R.; KAPLAN, R. S. How cost accounting systematically distorts product costs. Boston: Harvard Business Schools Pres, 1987.

CORRÊA, H. L.; GIANESI, I. G. N. Just in Time, MRP II e OPT: um enfoque estratégico. São Paulo: Atlas S.A., 1996.

CSILLAG, J. M. Análise do valor: metodologia do valor. São Paulo: Atlas, 1995.

DICIO. Dicionário Online De Português, 2014. Disponível em:

<http://www.dicio.com.br/determinante/>. Acesso em: 30 out. 2014. 
ELIAS, S. J. B, A análise do valor e a filosofia Just in Time. In: XXI Encontro Nacional de Engenharia de Produção, 2001, Salvador. Anais do XXI Encontro Nacional de Engenharia de Produção, 2001.

FELDMAN, D. H.; FOWLER, R. C. The nature(s) of Developmental Change: Piaget, Vygotsky, and the Transition Process. New Ideas in Psychology, v.15, n.3, p. 195-210, 1997. http://dx.doi.org/10.1016/S0732-118X(97)10001-0

FREESE, C. H. Wild Species as Commodities: The Dilemma of Socioeconomic vs. Ecological Sustainability. Bulletin of the Ecological Society of America, v.78, n.4, p.12-24, 1997. http://dx.doi.org/

GARRISON, R. H.; NOREEN, E. W.; BREWER, P. C. Contabilidade gerencial. 11. ed., Rio de Janeiro: LTC, 2007.

GHEMAWAT, P. A estratégia e o cenário dos negócios. Porto Alegre: Bookman, 2007.

GOHR, C. F.; SANTOS, L. C. Contexto, conteúdo e processo da mudança estratégica em uma empresa estatal do setor elétrico brasileiro. Revista de Administração Pública, v.45, n.6, 2011. http://dx.doi.org/10.1590/S0034-76122011000600004

HACKING, I. Mathematics, Science and Epistemology. British Journal for the Philosophy of Science, v.30, n.4, p.381-402, 1979.

HANSEN, D. R.; MOWEN, M. M. Gestão de custos. São Paulo: Pioneira, 2011.

HART, S. L.; MILSTEIN, M. B. Creating Sustainable Value. Academy of Management Executive, v.17, n.2, p.56-67, 2003. http://dx.doi.org/10.5465/AME.2003.10025194

HORNGREN, C. T.; DATAR, S. M.; RAJAN, M. V. Cost accounting: a managerial emphasis. 14. ed. New Jersey: Prentice Hall, 2011.

LINS, C. Sustentabilidade e geração de valor: a transição para o século XXI. Rio de Janeiro: Elsevier, 2010

MARX, K. Das kapital: kritik der politischen oekonomie, Hamburg: Erster Band, 1867.

MASLOW, A.H. A theory of human motivation. Psychological Review, v. 50, n.4, p.370-96, 1943. http://dx.doi.org/10.1037/h0054346

MILES, L. D. Techniques of value analysis and engineering. New York: Eleanor Miles Walker, 1989.

MONTGOMERY, C. A.; PORTER, M. E. Estratégia: a busca da vantagem da vantagem competitiva. Rio de Janeiro: Campus, 1998.

OHNO, T. Toyota production system: beyond large-scale production. Portland: Productivity Press, 1988

PEREIRA, M. F. Recursos Humanos em um contexto de reestruturação: uma revisão.

Revista de Administração. São Paulo, v.33, n.3, p. 47-55, 1998.

PETTIGREW, A. M. Shaping strategic change. London: Sage, 1992. 
PETTIGREW, A. M. Context and action in the transformation of the firm. Journal of Management Studies, v.24, n.6, p.649-670, 1987. http://dx.doi.org/10.1111/j.14676486.1987.tb00467.x

PORTER, M. E. Competitive advantage: creating and sustaining superior Performance. New York: Free Press, 1998.

PORTER, M. E. From Competitive advantage to corporate strategy. Harvard Business Review, v.65, n.3, 1987.

PORTER, M. E.; KRAMER, M. R. Creating shared value. Harvard Business Review, v. 89, n.1/2, p.62-77, 2011.

POSSAMAI, O. Análise de valor agregado. Apostila - Pós-Graduação em Engenharia Produção, Departamento de Engenharia Produção, Universidade Federal de Santa Catarina. Florianópolis, 2002.

RELVAS, T. R. S. Análise de cadeia de valor. In: ENCONTRO ANUAL DA ASSOCIAÇÃO NACIONAL DOS PROGRAMAS DE PÓS-GRADUAÇÃO EM ADMINISTRAÇÃO, 20, 1996, Angra dos Reis. Anais... Angra dos Reis, 1996.

ROTHER, M.; SHOOK, J. Learning to see: Value stream mapping to create value and eliminate muda. Massachusetts: The Lean Enterprise Institute, 1998.

SAVE International. Disponível em: <http://www.value-eng.org>. Acesso em: 7 Maio 2013.

SCHMIDT-PETRI, C. Classical utilitarianism from hume to mill. Economics and Philosophy, v.22, n.3, p.460-463, 2005.

SHANK, J. K. O custo focado no cliente. Revista HSM Management, São Paulo, n.19, 2000.

SMITH, A. An Inquiry into the nature and causes of the wealth of nations. London: W. Strahan, 1776.

SPIEGEL, H. W. The Growth of economic thought. North Carolina: Duke University Press, 1983.

STAINTON, T. Reason and Value: The Thought of Plato and Aristotle and the Construction of Intellectual Disability. Mental Retardation, v.39, n.6, p. 452-460. 2001. http://dx.doi.org/10.1352/0047-6765(2001)039<0452:RAVTTO>2.0.CO;2

TEIXEIRA, M. L. M. Valores Humanos e Gestão. São Paulo: Senac, 2008.

TURKYILMAZ, A.; GORENER, A.; BASER. H. Value stream mapping: case study in a water heater manufacturer. International Journal of Supply Chain Management, v.2, n.2, p.3239, 2013.

UEDA, K.; TAKENAKA, T.; VANCZA, J.; MONOSTORI, L. Value criation and decisionmaking in sustainable society. CIRP Annals - Manufacturing Technology, v.58, p.681700, 2009. http://dx.doi.org/10.1016/j.cirp.2009.09.010

VALENSTEIN, A. F. Pre-oedipal reconstructions in psychoanalysis. International Journal of Psycho-Analysis, v.70, p.433-442, 1989. 
VIEIRA, M. G. Avaliação do mapeamento do fluxo de valor como ferramenta da produção enxuta por meio de um estudo de caso. Florianópolis: Dissertação de mestrado. Engenharia Mecânica, Universidade Federal de Santa Catarina, 2006

WALTERS, D.; LANCASTER, G. Implementing value strategy trough the value chain. Management Decision, v.38, n.2, p.160-178, 2000.

http://dx.doi.org/10.1108/EUM0000000005344

WATKINS, J. Hobbes's System of Ideas: a study in the political significance of philosophical theories. London: Hutchinson, 1965.

WCED - World Commission on Environment and Development. Our Common Future. Oxford: Oxford University Press, 1987.

WOMACK, J. P.; JONES, D. T.; ROOS, D. The machine that changed the world. New York: Rawson Associates, 1990.

WOMACK, J. P.; JONES, D. T. Lean thinking: banish waste and create wealth in your corporation. New York: Simon \& Schuster, 1996.

WOMACK, J. P. Value Stream mapping. Manufacturing Engineering, v.136, n.5, p.145, 2006.

YOUNG, S. D.; O'BYRNE, S. F. EVA® e gestão baseada em valor: guia prático para implementação. Porto Alegre: Bookman, 2003.

ZAWISLAK, P. A. A produção enxuta e novos padrões de fornecimento em três montadoras de veículos no Brasil. In: SIMPÓSIO DE GESTÃO DA INOVAÇÃO TECNOLÓGICA, 21, 2000. são Paulo: Anais do XXI Simpósio de Gestão da Inovação Tecnológica, 2000.

ZURIFF, G. E. Philosophy of behaviorism. Journal of Experimental Analysis of Behavior, v.77, n.3, p.367-371, 2002. http://dx.doi.org/10.1901/jeab.2002.77-367

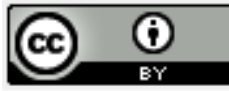

Artigo recebido em 21/11/2014 e aceito para publicação em 16/09/2015 DOI: http://dx.doi.org/ 10.14488/1676-1901.v15i4.1915 